\title{
Testing new ensemble forecasts of solar irradiance
}

\author{
J.M. Botana, A. Rodríguez, J.A. Gonzalez \\ Department of Chemical Engineering \\ School of Engineering, University of Santiago de Compostela \\ c/ Lope Gómez de Marzoa, s/n - Campus Vida, 15782 Santiago de Compostela (Spain) \\ Phone number: +34881816757, e-mail: jmbofe@gmail.com, angel.rodriguez@usc.es, ja.souto@usc.es
}

\begin{abstract}
The increment of solar energy production requires an accurate estimation of surface solar irradiance. A forecast of surface solar irradiance allows estimate the energy production, i.e., to minimize the fluctuations in the electric grid supply.

In this work a numerical weather forecast model provides surface solar radiation estimations over a coastal region with changeable weather and typically partially cloudy days. As direct model output over specific locations is not always accurate, an ensemble forecast with four members (including time and spatial combinations) is proposed and validated against measurements from three different weather stations in that region, along 1-year.

From this validation, statistics show that the best forecast is achieved with the ensemble member obtained by the linear combination of the solar radiation forecasted for the corresponding time $(\mathrm{H})$, one hour before $(\mathrm{H}-1)$, and one hour after $(\mathrm{H}+1)$. No improvement is obtained by spatial solar radiation combinations. Also, this ensemble forecast provides an estimation of the solar radiation uncertainty, which can be useful to provide flexible energy production forecasts.
\end{abstract}

\section{Key words}

Solar irradiance, WRF model, forecast ensemble, forecast validation.

\section{Introduction}

Global solar irradiance can be estimated in advance by a numerical weather forecast model, to be applied in the exploitation of solar energy systems. The use of this approach has been extensively tested [1]-[5]; however, differences over a specific location usually arise in regions with changeable weather and typical partially cloudy days [1], [4].

In [6], a high resolution implementation of WRF model [7] for Galicia, a changeable weather region, was done, in order to increase the spatial accuracy of the solar irradiance forecast. Also, an ensemble-in-time forecast was tested, with significant improvements using some both different WRF simulations and delayed outputs.

However, more complex and computational cost demanding approaches were also tested ([8],[9]) in other regions, with different performance. Therefore, a balance between every ensemble complexity and its accuracy must be considered.

In the current work, forecast uncertainty associated to the location (model grid vs. measurements location) is also considered, producing new ensemble members. A statistical assessment [9] against solar radiation measurements over three different locations is performed and, also, compared to the previous ensemble-in-time results. 

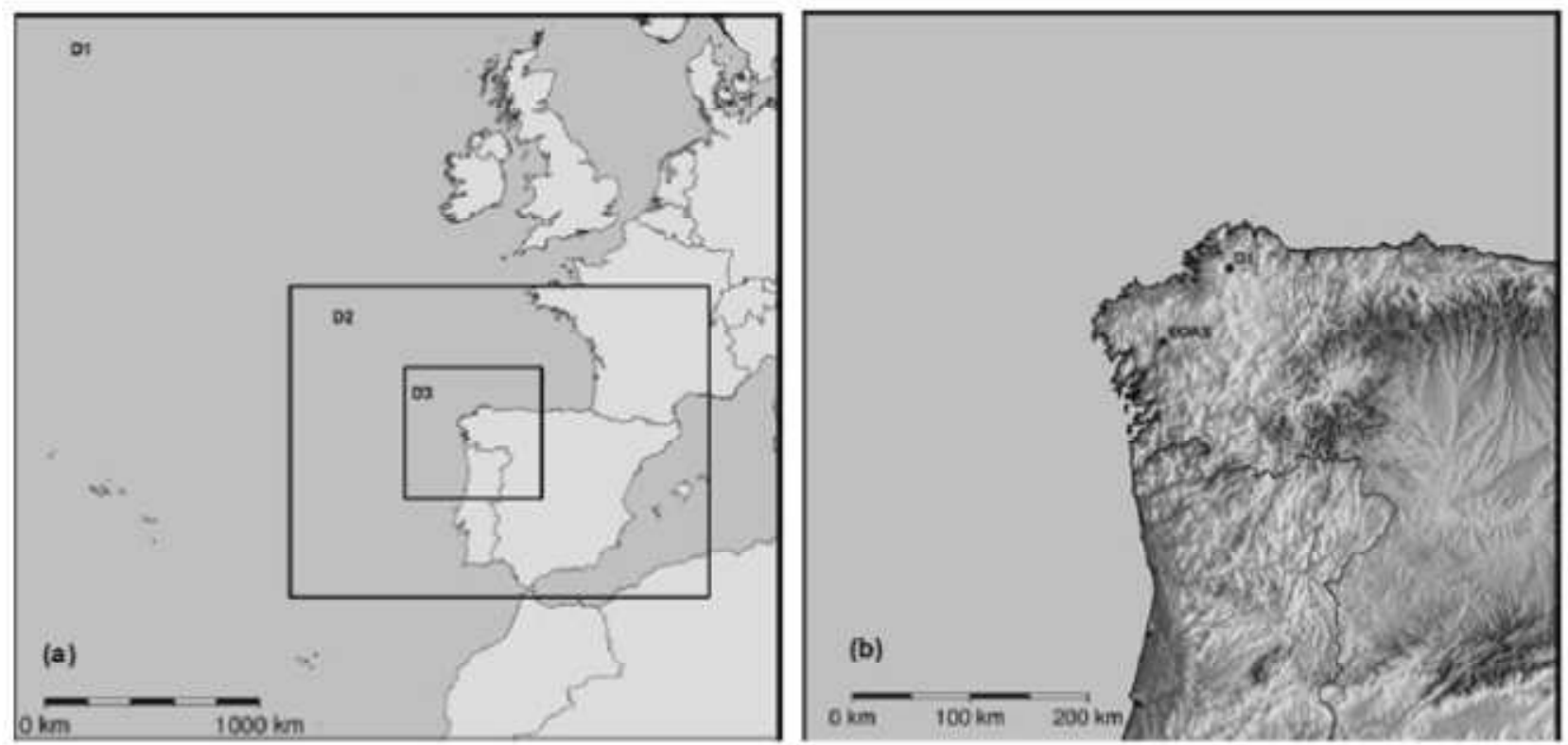

Fig. 1. (a) WRF nested domains and (b) locations of D1-A Mourela, EOAS-Santiago and CIS-Ferrol weather stations applied in the forecast validation.

\section{Materials and methods}

In this work a high resolution implementation of WRF model [6] for Galicia, a changeable weather region, was done, in order to increase the spatial accuracy of the solar irradiance forecast.

Surface solar irradiance hourly forecast for 72 hours was performed by WRF model, using its RRTM [10] and Dudhia [11] radiative transfer models in this testing region, and modeled downward short-wave radiation results were compared against measurements at three different locations. Considering the typical synoptic patterns around the region, this WRF configuration included three one-way nested domains with horizontal resolutions of 27, 9 and $3 \mathrm{~km}$ (Fig. 1a), in order to obtain a high resolution forecast. A variable distribution of vertical levels up to $21 \mathrm{~km}$, with more levels near the surface, was applied. Initial and boundary conditions were obtained from the Global Forecast System (NCEP-GFS) forecasts $\left(1^{\circ} \times 1^{\circ}\right.$ and 3 hours time interval). Elevation and land cover data were provided by the digital terrain model from the United States Geological Survey [7].

In spite of this high resolution forecast, during cloudy days some discrepancies between model results and measurements were expected; particularly, the uncertainty associated with solar irradiance forecasts at specific locations obtained directly from a grid model [3]. These differences are mainly because of the difficulty to forecast the clouds development and transport over a single location.

Therefore, as a solar irradiance forecast, an ensemble with four different members, including the direct output of WRF model and different linear combinations, were tested against measurements at three different locations (Fig. 1b) along one year. Ensemble members are computed to a grid cell 22 (Fig. 2) at $H$ hour. Also, Fig. 2 shows the surrounding grid cells around it which are considered in the spatial members.

\begin{tabular}{|c|c|c|}
\hline$R_{H 11}$ & $R_{H 12}$ & $R_{H 13}$ \\
\hline$R_{H 21}$ & $R_{H 22}$ & $R_{H 23}$ \\
\hline$R_{H 31}$ & $R_{H 32}$ & $R_{H 33}$ \\
\hline
\end{tabular}

Fig. 2. Cells grid positions in and around to the 22 central grid cell, applied in some ensemble members.

First member, namely M0, properly includes the WRF hourly solar irradiance forecast over a central grid cell 22 (Fig. 2), without any change (1).

$R_{H M 0}=R_{H 22}$

where $R_{H 22}$ is the WRF hourly solar irradiance forecast for the central grid cell.

Second member, namely $\mathrm{M} 1$, is a spatial linear combination of represented by the irradiances obtained by WRF model at hour $\mathrm{H}$ in the central grid cell 22 and the surrounding cells, as follows,

$$
\begin{aligned}
R_{H M 1} & =a_{0}+a_{1} R_{H 22}+ \\
& +a_{2}\left(R_{H 12}+R_{H 21}+R_{H 23}+R_{H 32}\right)+ \\
& +a_{3}\left(R_{H 11}+R_{H 13}+R_{H 31}+R_{H 33}\right)
\end{aligned}
$$

where $a_{0}, a_{1}, a_{2}$ and $a_{3}$ are the empirical adjusted parameters. 
Third member of the ensemble, namely M2, is a time linear combination of different WRF outputs at (22) central grid cell, for one hour before (namely $(H-1))$, the corresponding hour $(H)$ and the next hour $(H+1)$, according to the following expression,

$R_{H M 2}=b_{0}+b_{1} R_{H-122}+b_{2} R_{H 22}+b_{3} R_{H+122}$

where $b_{0}, b_{1}, b_{2}$ and $b_{3}$ are the empirical adjusted parameters.

The last member, namely M3, is a linear combination of the M1 and M2 members, following (4),

$R_{H M 3}=c_{0}+c_{1} R_{H M 1}+c_{2} R_{H M 2}$

where $\boldsymbol{c}_{\mathbf{0}}, \boldsymbol{c}_{\mathbf{1}}$ and $\boldsymbol{c}_{\mathbf{2}}$ are the empirical adjusted parameters.

A 72-hour operational forecast system, including a daily WRF model run, allows obtain these four members ensemble from just one WRF run per day. This is a significant computational time saving respect to typical ensemble approaches [8], [9]; and, every member can be validated against measurements in order to select the most accurate of them.

\section{Results}

Three different locations (Fig. 1b) at the NW of Galicia were selected for the forecasts testing: one in the Atlantic coast (CIS-Ferrol), 34 meters above sea level (asl-m), and the others placed inland, around $32 \mathrm{~km}$ (Santiago-EOAS, 255 asl-m) and $30 \mathrm{~km}$ (D1-A Mourela, 450 asl-m) far from the sea, respectively. CIS-Ferrol and Santiago-EOAS are weather stations classified as suburban and urban stations, respectively; whereas D1-A Mourela is a rural site. Measurements of global solar radiation were obtained from Class A pyranometers installed at every location.

The sunshine hours are even lower than the regional average (less than 2000 sunshine hours per year) in some of these stations, with values between 1600 and 1800 hours per year at the northern locations (CIS-Ferrol and
D1-A Mourela) and around 2000 hours at EOAS-Santiago station [6].

To assess the performance of the different solar irradiance forecasts, some statistics have been considered. The main score to compare forecast irradiance $\left(R_{f}\right)$ and measured irradiance $\left(R_{m}\right)$ was the root mean square error RMSE (eq. 4),

$$
R M S E=\sqrt{\frac{1}{N} \cdot \sum_{1}^{N}\left(R_{f}-R_{m}\right)^{2}}
$$

where $\mathrm{N}$ is the number of evaluated data pairs of hourly irradiance.

Furthermore, other two additional statistical measures were considered: the mean bias, $M S E$ (eq. 5) to describe systematic deviation of the forecast, and the mean absolute gross error, $M A G E$ (eq. 6), that considers a linear weighting of all deviations.

$$
\begin{gathered}
M S E=\frac{1}{N} \cdot \sum_{1}^{N}\left(R_{f}-R_{m}\right) \\
M A G E=\frac{1}{N} \cdot \sum_{1}^{N}\left|R_{f}-R_{m}\right|
\end{gathered}
$$

Relative values of these error measures ( $r R M S E$, $r M S E$, $r M A G E)$ are obtained by normalization to the mean ground measured irradiance of the testing period.

These statistical parameters for model evaluation were calculated using the dataset based on hourly global solar irradiance ground measurements from the aforementioned three weather stations. Experimental dataset used covers the period July $2010,1^{\text {st }}-$ July $2011,2^{\text {nd }}$. To identify night periods (not included) WMO criteria are applied [13], using a combination of sunrise and sunset times, and irradiance values below $120 \mathrm{~W} \cdot \mathrm{m}^{-2}$.

\begin{tabular}{|c|c|c|c|c|c|c|c|c|c|}
\hline & & \multicolumn{3}{|c|}{ M1 member } & \multicolumn{3}{|c|}{ M2 member } & \multicolumn{2}{|c|}{ M3 member } \\
\hline & & $a_{1}$ & $a_{2}$ & $a_{3}$ & $b_{1}$ & $b_{2}$ & $b_{3}$ & $c_{1}$ & $c_{2}$ \\
\hline \multirow{4}{*}{ CIS-Ferrol } & $\mathrm{D}+0$ & 0.0290 & 0.1142 & 0.1145 & 0.3105 & 0.3107 & 0.3106 & 0.5000 & 0.5000 \\
\hline & $\mathrm{D}+1$ & 0.0297 & 0.1176 & 0.1180 & 0.3221 & 0.3224 & 0.3216 & 0.5000 & 0.5000 \\
\hline & $\mathrm{D}+2$ & 0.0285 & 0.1135 & 0.1133 & 0.3104 & 0.3106 & 0.3104 & 0.5000 & 0.5000 \\
\hline & $\mathrm{D}+0$ & 0.0282 & 0.1129 & 0.1134 & 0.3127 & 0.3132 & 0.3117 & 0.5000 & 0.5000 \\
\hline \multirow[t]{3}{*}{ D1-A Mourela } & $\mathrm{D}+1$ & 0.0290 & 0.1163 & 0.1163 & 0.3208 & 0.3214 & 0.3213 & 0.5000 & 0.5000 \\
\hline & $D+2$ & 0.0283 & 0.1139 & 0.1139 & 0.3152 & 0.3153 & 0.3148 & 0.5000 & 0.5000 \\
\hline & $\mathrm{D}+0$ & 0.0292 & 0.1159 & 0.1154 & 0.3149 & 0.3151 & 0.3149 & 0.5000 & 0.5000 \\
\hline \multirow[t]{2}{*}{ EOAS-Santiago } & $\mathrm{D}+1$ & 0.0294 & 0.1176 & 0.1175 & 0.3234 & 0.3237 & 0.3233 & 0.5000 & 0.5000 \\
\hline & $\mathrm{D}+2$ & 0.0286 & 0.1145 & 0.1140 & 0.3149 & 0.3150 & 0.3143 & 0.5000 & 0.5000 \\
\hline
\end{tabular}

Table I. Adjusted coefficients of ensemble members M1, M2 and M3 in the weather stations (EOAS-Santiago, CIS-Ferrol and D1-A Mourela) calculated for three forecast horizons (D+0, D+1 and D+2). 
To calculate the empirical adjusted coefficients of the different ensemble members, following [14] two different datasets were considered,

- February and August data, as extreme seasonal months [15], to calculate the empirical adjusted coefficients.

- The rest of ten months (1-year period) were applied for forecast validation, in order to test the different ensemble members against measurements which are not used for their empirical adjustment.
Adjusted coefficients obtained are shown on Table I. for the members M1, M2, and M3 in each station. Notice that $a_{0} . b_{0}$ and $c_{0}$ coefficients are finally set to zero. as a previous adjustment shows that their values are very low in comparison to their members results. Therefore, they are neglected.

Considering the adjusted coefficients obtained for M1 member (Table I) the weights of the surrounding cells are higher than the weight of the station cell (Fig. 2). About M2 member, similar weights are obtained for $H,(H-1)$, and $(H+1)$ solar radiation direct forecasts: WRF model output tendency is quite accurate in time. About M3 member, both coefficients are equal.

Table II. Absolute (RMSE. MAGE and MSE) and relative (rRMSE. rMAGE and rMSE) statistics from the validation of solar irradiance forecast in the three weather stations. Direct model results (M0) and different ensemble members (M1, M2, M3) were validated for three forecasting horizons $(\mathrm{D}+0, \mathrm{D}+1$, and $\mathrm{D}+2)$.

\begin{tabular}{|c|c|c|c|c|c|c|c|c|c|c|c|c|c|}
\hline & & $\begin{array}{c}\text { MSE } \\
\left(\mathrm{Wm}^{-2}\right)\end{array}$ & $\begin{array}{c}\text { MAE } \\
\left(\mathrm{Wm}^{-2}\right)\end{array}$ & $\begin{array}{l}\text { RMSE } \\
\left(\mathrm{Wm}^{-2}\right) \\
\end{array}$ & $\begin{array}{c}\text { rMSE } \\
(\%)\end{array}$ & $\begin{array}{c}\text { rMAE } \\
(\%)\end{array}$ & $\begin{array}{c}\text { rRMSE } \\
(\%)\end{array}$ & $\begin{array}{c}\text { MSE } \\
\left(\mathrm{Wm}^{-2}\right)\end{array}$ & $\begin{array}{c}\text { MAE } \\
\left(\mathrm{Wm}^{-2}\right)\end{array}$ & $\begin{array}{l}\text { RMSE } \\
\left(\mathrm{Wm}^{-2}\right) \\
\end{array}$ & $\begin{array}{c}\text { rMSE } \\
(\%)\end{array}$ & $\begin{array}{c}\text { rMAE } \\
(\%)\end{array}$ & $\begin{array}{c}\text { rRMSE } \\
(\%)\end{array}$ \\
\hline & & \multicolumn{6}{|c|}{ M0 member (WRF direct output) } & \multicolumn{6}{|c|}{ M1 member } \\
\hline \multirow{3}{*}{$\begin{array}{l}\text { CIS- } \\
\text { Ferrol }\end{array}$} & $\mathrm{D}+0$ & 32.21 & 157.01 & 449.83 & 6.92 & 33.72 & 96.60 & 6.54 & 129.57 & 437.70 & 1.40 & 27.82 & 93.99 \\
\hline & $\mathrm{D}+1$ & 29.79 & 162.60 & 457.50 & 6.43 & 35.08 & 98.72 & 16.13 & 144.14 & 449.05 & 3.48 & 31.10 & 96.89 \\
\hline & $\mathrm{D}+2$ & 19.04 & 177.86 & 463.19 & 4.12 & 38.46 & 100.15 & -8.57 & 150.65 & 450.61 & -1.85 & 32.57 & 97.43 \\
\hline \multirow{3}{*}{$\begin{array}{c}\text { D1-A } \\
\text { Mourela }\end{array}$} & $\mathrm{D}+0$ & 43.47 & 194.32 & 246.49 & 9.54 & 42.66 & 54.11 & 6.18 & 173.46 & 219.08 & 1.36 & 38.08 & 48.10 \\
\hline & +1 & 38.80 & 196.46 & 249.47 & 8.54 & 43.26 & 54.93 & 19.03 & 180.08 & 228.68 & 4.19 & 39.65 & 50.36 \\
\hline & $\mathrm{D}+2$ & 22.85 & 204.36 & 258.08 & 5.06 & 45.28 & 57.18 & -5.81 & 185.45 & 233.49 & -1.29 & 41.09 & 51.73 \\
\hline \multirow{3}{*}{$\begin{array}{l}\text { EOAS- } \\
\text { Santiago }\end{array}$} & $\mathrm{D}$ & 39.88 & $0.2 J$ & 181.37 & 8.45 & 26.76 & 38.44 & 16.32 & 109.45 & 159.63 & 3.46 & 23.20 & 33.83 \\
\hline & $\mathrm{D}+1$ & 39.99 & 133.99 & 190.73 & 8.46 & 28.35 & 40.35 & 23.54 & 119.15 & 170.82 & 4.98 & 25.21 & 36.14 \\
\hline & $\mathrm{D}+2$ & 1.84 & 38.02 & 197.69 & 6.77 & 29.35 & 42.04 & 0.75 & 120.26 & 173.70 & 0.16 & 25.58 & 36.94 \\
\hline & & \multicolumn{6}{|c|}{ M2 member } & \multicolumn{6}{|c|}{ M3 member } \\
\hline \multirow{4}{*}{$\begin{array}{l}\text { CIS- } \\
\text { Ferrol }\end{array}$} & $\mathrm{D}+0$ & -1.79 & 119.98 & 435.02 & -0.38 & 25.76 & 93.42 & 2.38 & 120.79 & 434.75 & 0.51 & 25.94 & 93.36 \\
\hline & $\mathrm{D}+1$ & 13.01 & 130.77 & 441.96 & 2.81 & 28.22 & 95.36 & 14.57 & 133.12 & 443.89 & 3.14 & 28.72 & 95.78 \\
\hline & $\mathrm{D}+2$ & -14.07 & 140.59 & 445.49 & -3.04 & 30.40 & 96.32 & -11.32 & 141.85 & 446.40 & -2.45 & 30.67 & 96.52 \\
\hline & $\mathrm{D}+0$ & 12.21 & 155.76 & 200.23 & 2.68 & 34.20 & 43.96 & 9.20 & 161.20 & 205.46 & 2.02 & 35.39 & 45.11 \\
\hline \multirow{2}{*}{$\begin{array}{c}\text { D1-A } \\
\text { Mourela }\end{array}$} & $\mathrm{D}+1$ & 20.78 & 160.82 & 210.03 & 4.58 & 35.41 & 46 & 19.90 & 16 & 21 & 4. & 36 & 47.36 \\
\hline & $\mathrm{D}+2$ & -3.08 & 167.41 & 215.55 & -0.68 & 37.09 & 47.76 & -4.45 & 173.49 & 220.83 & -0.99 & 38.44 & 48.93 \\
\hline \multirow{3}{*}{$\begin{array}{l}\text { EOAS- } \\
\text { Santiago }\end{array}$} & $\mathrm{D}+0$ & 11.67 & 102.23 & 147.42 & 2.47 & 21.66 & 31.24 & 14.00 & 101.76 & 149.74 & 2.97 & 21.57 & 31.73 \\
\hline & $\mathrm{D}+1$ & 24.77 & 111.16 & 160.13 & 5.24 & 23.52 & 33.87 & 24.16 & 111.49 & 161.57 & 5.11 & 23.59 & 34.18 \\
\hline & $\mathrm{D}+2$ & 3.75 & 113.30 & 163.42 & 0.80 & 24.10 & 34.76 & 2.25 & 113.37 & 165.03 & 0.48 & 24.11 & 35.10 \\
\hline
\end{tabular}

Table II shows the achieved statistics of the different ensemble members and forecast horizons at the three testing sites. About the WRF direct output, M0 member, MSE values show an average overestimation of the solar radiation, which is similar in the three locations and the three forecast horizons (D+0, D+1, and D+2). Curiously, MSE decreases as forecast horizon increases (D+2 MSE is lower than D+1). However, RMSE increases following the forecast horizon, as expected. This can be explained because the longest forecasts are less variable, so MSE is lower; however, that lower variability reduces the model capability to reproduce the natural solar radiation fluctuations, so RMSE is higher.

RMSE results also show that WRF direct output performs worse at CIS-Ferrol, due to the local conditions of this coastal site affected by sea aerosol and fog, which are not properly reproduced by the numerical model. In fact, D1-Mourela is also affected by typical river basin foggy conditions.

M1, M2, and M3 members reduce rRMSE respect to M0 direct model output. Average reductions of $7.87 \%$ with 
M1, $12.63 \%$ with M2, and $11.56 \%$ with M3, are achieved. Therefore, the best performance (lowest rRMSE) is obtained with M2 member: Linear combination of the solar radiation at $H,(H-1)$, and $(H+1)$ times is the best solution. In fact, although M3 member is the most complex, it cannot improve M2 results. Finally, M1 member gets the highest rRMSE, between the linear combination members.

Average rRMSE reduction with M2 member (respect to M0) is different depending on the station: At CIS-Ferrol the average rRMSE reduction is $3.5 \%$, at D1-A Mourela, $17.02 \%$, and at EOAS-Santiago, $17.37 \%$. Average rRMSE reduction at the three locations is $12.63 \%$. For instance, in [16] rRMSE reductions below $15 \%$ are achieved, using the Canadian Global Environmental Multiscale model as direct output and applying a spatial average and Kalman filter along 1-year to reduce the model output errors. Using the US National Digital Forecast Database, in [2] an average RMSE of $157 \mathrm{~W} \cdot \mathrm{m}^{-2}$ was obtained over seven stations of SUFRAD network along 1-year. More recently, in [6] a similar method was applied to improve direct model output over the same three stations considered in ths work, but their improvement of rRMSE was lower, with an average reduction of $12.5 \%$.

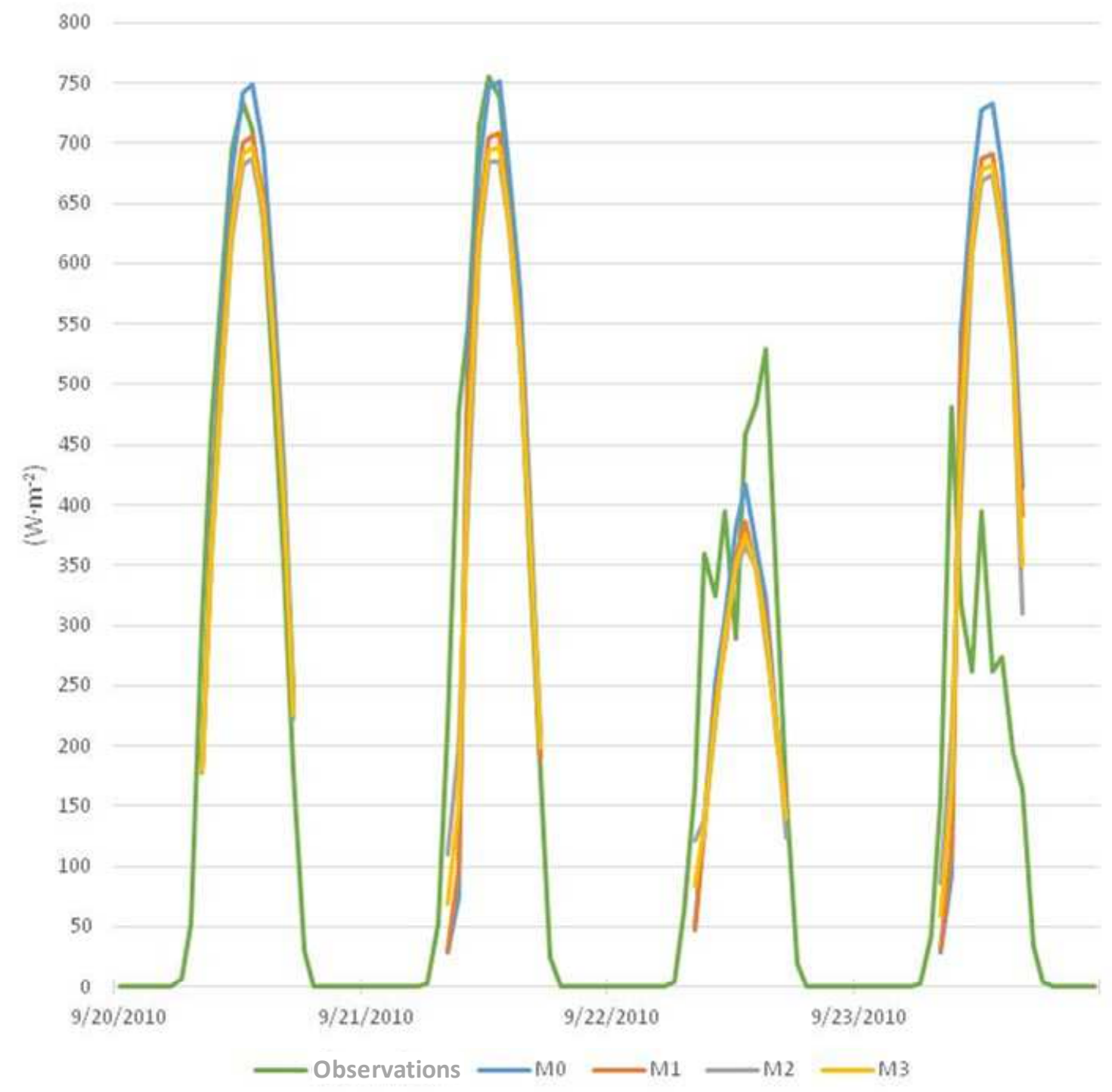

Fig. 3. Forecasted (ensemble D+2 members) and observed global solar radiation at EOAS-Santiago station, along 20-23 September 2010.

As an example, time series of the different D+2 forecast members and observations at EOAS-Santiago station along 20-23 September 2010 are shown in Fig. 3. Better agreement is achieved during the first two forecast days, as both are clear sky days. However, clouds during 22-23 September reduce the forecasts performance: The significance of clouds modeling in numerical weather forecast is even higher than the radiative transfer modeling.

\section{Conclusions}

In this work an experimental validation of different solar radiation forecasts was done: A deterministic numerical weather forecast and an ensemble forecast with four members, including the direct output of the weather forecast. Weather forecast direct output was provided by WRF model, using its RRTM and Dudhia radiative transfer models. Ensemble forecast includes direct output M0 member, and three different linear combinations of 
WRF outputs: M1 (spatial), M2 (time), and M3 (both spatial and time) members.

Different datasets were applied to M1, M2, and M3 empirical adjustment and the four members validation. Any combination members achieve better results than direct model output M0 member. Also, the best validation statistics were obtained using M2 member, which corresponds to time linear combination. Both spatial and time combination (M3) does not improve the solar radiation forecast.

Apart from the improvements obtained with the ensemble members, the availability of four different members allow estimate the forecast spread, in order to take into account the solar radiation forecast uncertainty in the exploitation of solar energy systems.

\section{Acknowledgements}

Solar radiation measurements were provided by MeteoGalicia (CIS-Ferrol and EOAS-Santiago stations) and As Pontes Power Plant (A Mourela station).

This work was developed as part of the MSc Thesis of J.M. Botana in the MSc in Renewable and Sustainable Energies, University of Santiago de Compostela.

\section{References}

[1] Prabha. T.. Hoogenboom. G.. "Evaluation of solar irradiance at the surface inferences from in situ and satellite observations and a mesoscale model" in Theor. Appl. Climatol., 2010, 102. 455-469.

[2] Perez. R.. Kivalov. S.. Schlemmer. J.. Hemker. K.. Renné. D.. Hoff. T. E.. "Validation of short and medium term operational solar radiation forecasts in the US" in Sol. Energy. 2010, 84, 2161-2173.

[3] Lorenz. E.. Hurka. J.. Heinemann. D.. Beyer H.G.. "Irradiance Forecasting for the Power Prediction of GridConnected Photovoltaic Systems" in IEEE Journal of Special Topics in Earth Observations and Remote Sensing, 2009a, 2, 210.

[4] Lorenz. E.. Remund. J.. Müller. S.C.. Traunmüller. W.. Steinmaurer. G.. Pozo. D.. Ruiz-Arias. J.A.. Lara. V.. Ramírez. L.. Gaston. M.. Kurz. C.. Pomares. L.M.. Geijo. C.. "Benchmarking of different approaches to forecast solar irradiance", in: Proceedings of 24 European Photovoltaic and Solar Energy Conference and Exhibition, Hamburg 2009b, (Germany), $10 \mathrm{pp}$.

[5] Zamora. R.J.. Dutton. E.G.. Trainer. M.. McKeen. S.A. Wilczak. J.M.. Hou. Y.. "The accuracy of solar irradiance calculations used in mesoscale numerical weather prediction" in Mon. Weather Rev. 2005, 133, 783-792.

[6] Díaz. D.. Souto. J.A.. Rodríguez. A.. Saavedra. S.. Casares. J.J. "An ensemble-in-time forecast of solar irradiance" in Proceedings of the International Conference on Renewable Energies and Power Quality (ICREPQ'12), Santiago de Compostela (Spain), 2012, 5 pp.

[7] Skamarock. W.C.. Klemp. J.B.. "A time-split non-hydrostatic atmospheric model" in Journal of Computational Physics. 2008. 227, pp. 3465-3485.

[8] F. Molteni. R. Buizza. T. N. Palmer. and T. Petroliagis. "The ECMWF Ensemble prediction system: methodology and validation" in Quarterly Journal of the Royal Meteorological Society, 1996, vol. 122, no. 529, pp. 73-119.
[9] M. Wei, Z. Toth, R. Wobus, and Y. Zhu, "Initial perturbations based on the Ensemble transform (ET) technique in the NCEP global operational forecast system", Tellus, 2008, vol. 60 , no. 1 , pp. 62-79.

[10] Mlawer, E. J., Taubman, S. J., Brown, P. D. and Michael J. Iaocono, S. A. C. (1997) "Radiative transfer for inhomogeneous atmospheres: RRTM, a validated correlated-k model for the longwave" in Journal of Geophysical Research, pp. 1666316682.

[11] Dudhia, J. (1989) "Numerical study of convection observed during the winter monsoon experiment using a mesoscale two-dimensional model" in Journal of the Atmospheric Sciences, pp. 3077-3107.

[12] Precedo Ledo, A., Sancho Comíns, J., "Atlas de Galicia" (Tomo I: Medio Natural), Sociedade para o Desenvolvemento Comarcal de Galicia, Xunta de Galicia, 2001, 137-155.

[13] WMO (2003). "Manual on the global observing system". Geneva: Secretariat of the World Meteorological Organization.

[14] Jollife. I. T. and Stephenson, B. (2003). "Forecast verification: a practioner's guide in atmospheric science". Chichester. West Sussex. England: Wiley.

[15] WMO (2000). "Standardised verfication system (SVS) for long-range forecast (LRF)".

Available at: www.wmo.int/pages/prog/www/DPS/SVS-forLRF.html

[16] Pelland, S., Galanis, G. and Kallos, G. (2013). "Solar and photovoltaic forecasting through post-processing of the Global Environmental Multiscale numerical weather prediction model" in Progress in Photovoltaics: Research and Applications, 2013, vol. 21, pp. 284-296. 